\title{
Chemical stress contribution in bacterial biofilm formation
}

Olga Iungin ${ }^{1,2}$ and Andrew Spiers ${ }^{3}$

${ }^{1}$ Kyiv National University of Technologies and Design, Kyiv, Ukraine (olgaungin@gmail.com)

${ }^{2}$ Institute of Molecular Biology and Genetics of the National Academy of Sciences of Ukraine, Kyiv, Ukraine

(olgaungin@gmail.com)

${ }^{3}$ School of Applied Sciences, Abertay University, Dundee, United Kingdom (a.spiers@abertay.ac.uk)

Background: The use of different chemicals for agriculture, industry and mining has caused pollution of agrarian soils which provokes changes in rhizosphere microflora. We have studied 10 bacterial strains isolated from a winter wheat Cd-polluted field in Ukraine by their taxonomic position, biochemical properties and resistance to 3 classes of toxicants: heavy metals $\left(\mathrm{Cu}^{2+}, \mathrm{Cd}^{2+}\right)$, nonmetals (perchlorate-ion), organic xenobiotic (1-chloro-4-nitrobenzene, CNB).

Objectives: To study the effect of toxicants on the biofilm-formation ability of individual strains and a mixed community.

Methods: Biofilm characteristics (total microcosm growth, biofilm strength and attachment to the microcosm walls) were studied by combined biofilm assay $(n=4)$ with four treatments including $100 \mathrm{mg} / \mathrm{L} \mathrm{Cu}^{2+}, 25 \mathrm{mg} / \mathrm{L} \mathrm{Cd}^{2+}, 300 \mathrm{mg} / \mathrm{L} \mathrm{ClO}_{4}{ }^{-}$, and $100 \mathrm{mg} / \mathrm{L} \mathrm{CNB}$, with correlations and Principal component analysis (PCA) used to investigate data.

Results: We found that microbial community had a greater resistance to the toxicants compare to individual strains. The presence of heavy metals increased the strength of biofilms, and in most cases growth and biofilm strength were positively correlated. However, in the presence of $\mathrm{Cd}^{2+}$ this correlation was lost. Perchlorate affected bacteria, increasing mucus production and biofilm strength though it also reduced attachment levels. Finally, we also found that CNB could be used as a source of Carbon and energy during biofilm-formation. 